\title{
Coronary Angiography after Cardiac Arrest - The Right Timing or the Right Patients?
}

\author{
Benjamin S. Abella \\ University of Pennsylvania \\ David F. Gaieski \\ Thomas Jefferson University
}

Follow this and additional works at: https://jdc.jefferson.edu/emfp

Part of the Cardiology Commons, and the Emergency Medicine Commons

Let us know how access to this document benefits you

\section{Recommended Citation}

Abella, Benjamin S. and Gaieski, David F., "Coronary Angiography after Cardiac Arrest - The Right Timing or the Right Patients?" (2019). Department of Emergency Medicine Faculty Papers.

Paper 87.

https://jdc.jefferson.edu/emfp/87

This Article is brought to you for free and open access by the Jefferson Digital Commons. The Jefferson Digital Commons is a service of Thomas Jefferson University's Center for Teaching and Learning (CTL). The Commons is a showcase for Jefferson books and journals, peer-reviewed scholarly publications, unique historical collections from the University archives, and teaching tools. The Jefferson Digital Commons allows researchers and interested readers anywhere in the world to learn about and keep up to date with Jefferson scholarship. This article has been accepted for inclusion in Department of Emergency Medicine Faculty Papers by an authorized administrator of the Jefferson Digital Commons. For more information, please contact: JeffersonDigitalCommons@jefferson.edu. 
E D I T O R I A L S

\title{
Coronary Angiography after Cardiac Arrest - The Right Timing or the Right Patients?
}

\author{
Benjamin S. Abella, M.D., M.Phil., and David F. Gaieski, M.D.
}

The treatment of patients who are comatose after out-of-hospital cardiac arrest involves a complex, multidisciplinary approach that includes the use of targeted temperature management, aggressive hemodynamic management, electroencephalographic monitoring, and consideration of coronary angiography. ${ }^{1}$ However, studies suggest that despite these interventions, 30 to $50 \%$ of these patients die before hospital discharge, and a substantial percentage of long-term survivors have neurologic and cardiac sequelae., ${ }^{2,3}$

Although clinically significant coronary disease is common in patients who have cardiac arrest, ${ }^{4}$ the selection of patients for coronary angiography remains controversial. The general consensus is that comatose patients who have had cardiac arrest with evidence of ST-segment elevation myocardial infarction (STEMI) on electrocardiography (ECG) should undergo immediate coronary angiography; beyond this group, however, consensus is elusive. One difficulty in determining which patients should undergo coronary angiography is that identification of patients who have had an arrest from a coronary cause is surprisingly challenging when there is no evidence of STEMI on ECG. A previous observational study has shown that the initial arrest rhythm, troponin levels, and ECG findings are poor predictors of acute coronary lesions that require intervention. ${ }^{5}$ Furthermore, even among patients for whom acute coronary syndromes are the cause of the cardiac arrest, the appropriate timing of coronary angiography is unknown. The multicenter, randomized Coronary Angiography after Cardiac Arrest (COACT) trial, ${ }^{6}$ the results of which are now reported in the Journal, seeks to address the following question: in patients who have had an out-of-hospital cardiac arrest, is a strategy of immediate coronary angiog- raphy better than a strategy of delayed angiography with respect to survival at 90 days?

A cohort of 552 patients who were unconscious after cardiac arrest and had an initial shockable rhythm but no evidence of STEMI on ECG were randomly assigned in a 1:1 ratio to undergo immediate coronary angiography after resuscitation or delayed coronary angiography during hospitalization. The median time from arrest to coronary angiography was 2.3 hours in the immediate angiography group and 121.9 hours in the delayed angiography group. Overall survival at 90 days was not significantly different between the two groups $(64.5 \%$ of patients in the immediate angiography group and $67.2 \%$ in the delayed angiography group were alive at 90 days). These results suggest that coronary angiography does not have to be performed immediately in patients who have had cardiac arrest without STEMI. This finding is consistent with results from trials involving patients with acute coronary syndromes with neither STEMI nor cardiac arrest, for whom delayed coronary angiography yielded outcomes similar to those with immediate coronary angiography.

Although the COACT trial represents a carefully performed and well-documented trial conducted in a challenging clinical setting, it is important to highlight a fundamental limitation. Acute unstable coronary lesions were found in less than $20 \%$ of the total trial cohort, and coronary interventions were performed in less than $40 \%$ of the patients. That is, the majority of patients who had cardiac arrest and underwent angiography did not have clinically significant coronary lesions, and thus only a small fraction of the trial population would be affected by the timing of coronary angiography - or the performance of coronary angiography at all. There- 
fore, the results of the trial should be interpreted with caution. This problem of appropriate patient selection has been a critical limitation in other trials involving patients with cardiac arrest, including the landmark Thrombolysis in Cardiac Arrest (TROICA) trial. ${ }^{7}$ In that trial, patients who had out-of-hospital cardiac arrest and were randomly assigned to either thrombolytic therapy or placebo had similar outcomes, yet only a small fraction of these patients probably had acute thrombotic disease.

If the current trial had used more specific inclusion criteria, it could have enriched the cohort for patients with probable coronary disease, and very different outcomes might have resulted. In subgroup analyses, patients over the age of 70 years and patients with a history of coronary disease appeared to be more likely to benefit from immediate coronary angiography than younger patients and patients without a documented history of coronary disease (details are provided in the Supplementary Appendix of the article, available at NEJM.org). In addition, the trial design did not take into account clinical context, such as acute chest pain or other symptoms of coronary ischemia, which are known to often precede a cardiac arrest that has a coronary cause. ${ }^{8}$

The current trial also highlights the challenges inherent in prioritization of interventions after a cardiac arrest. Resuscitation guidelines recommend that targeted temperature management should be implemented promptly after resuscitation; yet often, coronary angiography takes precedence, which leads to delayed use of targeted temperature management. In the COACT trial, the median time to target temperature was 5.4 hours in the immediate angiography group and 4.7 hours in the delayed angiography group; whether this delay attenuated a potential survival benefit of immediate coronary angiography remains unknown. It is also important to stress that most in-hospital deaths that occur among patients who have been resuscitated after cardiac arrest are due to neurologic injury rather than to cardiac complications; in this trial, more than $60 \%$ of deaths were due to neurologic injury, which had frequently led to discontinuation of treatment.

The COACT trial represents an important step forward in the care of patients after a cardiac arrest, and the results suggest that for the majority of comatose patients who have had a car- diac arrest without evidence of STEMI, coronary angiography need not be performed immediately. Further work will be required to better define personalized treatment strategies for selected patients after cardiac arrest. Two multicenter investigations are currently under way; the ACCESS trial (ClinicalTrials.gov number, NCT03119571) and the Direct or Subacute Coronary Angiography in Out-of-hospital Cardiac Arrest trial (DISCO; NCT02309151) are investigating the timing of coronary angiography after cardiac arrest. It will be useful to compare the results of these trials with those of the COACT trial., ${ }^{90}$ The current trial also highlights the daunting challenges that remain in determining how interventions after cardiac arrest can affect patient outcomes. Addressing these challenges will require multidisciplinary efforts, with the important goal of increasing the likelihood of survival and improving quality of life for patients after cardiac arrest.

Disclosure forms provided by the authors are available with the full text of this editorial at NEJM.org.

From the Center for Resuscitation Science and Department of Emergency Medicine, University of Pennsylvania Perelman School of Medicine (B.S.A.), and the Department of Emergency Medicine, Jefferson Medical College (D.F.G.) — both in Philadelphia.

This editorial was published on March 18, 2019, at NEJM.org.

1. Callaway CW, Donnino MW, Fink EL, et al. Post-cardiac arrest care: 2015 American Heart Association guidelines update for cardiopulmonary resuscitation and emergency cardiovascular care. Circulation 2015;132:Suppl 2:S465-S482.

2. Nielsen $\mathrm{N}$, Wetterslev J, Cronberg T, et al. Targeted temperature management at $33^{\circ} \mathrm{C}$ versus $36^{\circ} \mathrm{C}$ after cardiac arrest. N Engl J Med 2013;369:2197-206.

3. Elmer J, Rittenberger JC, Coppler PJ, Guyette FX, Doshi AA, Callaway CW. Long-term survival benefit from treatment at a specialty center after cardiac arrest. Resuscitation 2016;108:48-53. 4. Jentzer JC, Scutella M, Pike F, et al. Early coronary angiography and percutaneous coronary intervention are associated with improved outcomes after out of hospital cardiac arrest. Resuscitation 2018;123:15-21.

5. Gonzalez MR, Esposito EC, Leary M, et al. Initial clinical predictors of significant coronary lesions after resuscitation from cardiac arrest. Ther Hypothermia Temp Manag 2012;2:73-7.

6. Lemkes JS, Janssens GN, van der Hoeven NW, et al. Coronary angiography after cardiac arrest without ST-segment elevation. N Engl J Med 2019;380:1397-407.

7. Böttiger BW, Arntz H-R, Chamberlain DA, et al. Thrombolysis during resuscitation for out-of-hospital cardiac arrest. $N$ Engl J Med 2008;359:2651-62.

8. Marijon E, Uy-Evanado A, Dumas F, et al. Warning symptoms are associated with survival from sudden cardiac arrest. Ann Intern Med 2016;164:23-9.

9. Yannopoulos D, Aufderheide TP. The ACCESS trial (http:// grantome.com/grant/NIH/R01-HL133818-01).

10. Lagedal R, Elfwén L, James S, et al. Design of DISCO - DIrect or Subacute Coronary angiography in Out-of-hospital cardiac arrest study. Am Heart J 2018;197:53-61.

DOI: 10.1056/NEJMe1901651

Copyright $\odot 2019$ Massachusetts Medical Society. 